\title{
Políticas de democratização da educação superior brasileira: limites e desafios para a próxima década
}

\author{
Maria de Fátima Costa de Paula
}

Resumo: $\mathrm{O}$ artigo tem como objetivo discutir as políticas de democratização adotadas nas universidades federais brasileiras, implementadas a partir do Governo Lula, tais como Programa de Apoio a Planos de Reestruturação e Expansão das Universidades Federais (REUNI), Política de Cotas para ingresso de estudantes de escolas públicas, com vagas reservadas para setores de baixa renda e para as minorias étnicas e Políticas de Assistência Estudantil. A pesquisa baseia-se em revisão bibliográfica e análise documental sobre o tema. A primeira parte do texto traz um panorama da educação superior brasileira nas últimas décadas e a segunda parte analisa os problemas e limites dessas políticas, sobretudo no que se refere à inclusão das camadas desfavorecidas socialmente e das minorias étnicas nos cursos de alta demanda / elevado prestígio social. O texto demonstra que o incremento das políticas de acesso e de assistência estudantil, com aumento de vagas e ingressantes, não tem sido acompanhado da permanência dos estudantes no sistema, com taxas de diplomação e de conclusão dos cursos de graduação decrescentes, nos últimos anos. Nessa perspectiva, inclusão e exclusão, acesso/permanência/evasão devem ser vistos em conjunto e não separadamente. Nas considerações finais, são levantadas questões no sentido de problematizar a inclusão de novos perfis de estudantes em um modelo de universidade que, em grande medida, não se alterou, sendo apontados os principais desafios para a próxima década.

Palavras-chave: Políticas de democratização. Universidades federais. Limites. Desafios.

\section{Democratization policies of the Brazilian higher education: limits and challenges for the next decade}

Abstract: The article aims to discuss the democratization policies adopted in the Brazilian Federal universities, implemented from Lula's Government, such as Program Support the Restructuring Plans and Expansion of Federal Universities, Quota policy for admission of students from public schools with vacancies reserved for low-income sectors and for ethnic minorities and Student Assistance policies. The research is based on literature review and analysis of documents on the subject. The first part of the text brings a panorama of Brazilian higher education in recent decades and the second part analyzes the problems and limits of such policies, in particular as regards the inclusion of socially disadvantaged layers and of ethnic minorities in high-demand courses/high social prestige. The text demonstrates that the development of access policies and student assistance, with an increase in vacancies and in the entrance of students, has not been accompanied by the permanence of students in the system, with graduation and completion rates of undergraduate courses declining in recent years. In this respect, inclusion and exclusion, access/permanence /dropout rates must be seen together and not separately. In the final considerations are raised questions in order to discuss the inclusion of new profiles of students in a university model that largely has not changed, being pointed the main challenges for the next decade.

Key words: Democratization policies. Federal universities. Limits. Challenges. 


\section{Introdução}

$\mathrm{O}$ artigo tem como objetivo discutir as políticas de inclusão adotadas nas universidades federais brasileiras, implementadas a partir do Governo Lula, apontando os problemas relacionados ao acesso e à permanência dos estudantes na educação superior.

A primeira parte do texto traça um panorama da educação superior brasileira nas últimas décadas, trazendo dados sobre instituições e matrículas na atualidade, nos setores público e privado. Aborda-se, ainda, o desenvolvimento do ensino superior a partir dos anos 1960, tendo como marco a Reforma Universitária de 1968.

A segunda parte do artigo analisa os problemas e limites das políticas de inclusão na educação superior, sobretudo no que se refere à inclusão das camadas desfavorecidas socialmente e das minorias étnicas nos cursos de alta demanda / elevado prestígio social. O texto demonstra que o incremento das políticas de acesso e de assistência estudantil, a partir do Governo Lula, com aumento de vagas e ingressantes, não tem sido acompanhado da permanência dos estudantes no sistema, com taxas de diplomação e de conclusão dos cursos de graduação decrescentes, nos últimos anos.

Nessa perspectiva, inclusão e exclusão, acesso/permanência/evasão devem ser vistos em conjunto e não separadamente. Os órgãos oficiais do governo, como o Instituto Nacional de Estudos e Pesquisas Educacionais Anísio Teixeira (INEP) do Ministério da Educação do Brasil (MEC), assim como as Instituições de Educação Superior (IES) não possuem dados consistentes sobre evasão, havendo ainda uma grande lacuna a respeito desse problema. Ou seja, há um silêncio sobre esse problema que sangra as nossas IES, fazendo com que o discurso sobre a democratização da educação superior torne-se vazio, pois o ciclo da democratização não se completa.

Nas considerações finais, são levantadas algumas questões no sentido de problematizar a inclusão de novos perfis de estudantes em um modelo de universidade que, em grande medida, não se alterou, sendo apontados alguns desafios para a próxima década. Nesse sentido, as universidades federais devem se reestruturar internamente, abrir-se para as inovações pedagógicas, implodir sistemas de poder enrijecidos, romper com preconceitos, de forma a se tornarem aptas para receber esta nova parcela da população historicamente excluída do ensino superior.

\section{Panorama da educação superior brasileira nas últimas décadas}

A Reforma Universitária de 1968 e as políticas públicas elaboradas nos governos de Fernando Henrique Cardoso são fundamentais para compreender a "escalada privatista" do ensino superior na atualidade, conforme indicam os dados do Censo da Educação Superior de 2015: as matrículas (nas modalidades presencial e a distância) concentram-se nas instituições privadas, com mais de seis milhões de estudantes (6.075.152), enquanto o setor público absorve apenas cerca de um milhão e novecentos mil (1.952.145) estudantes em sua rede. Ou seja, 76\% das matrículas estão nas instituições privadas e $24 \%$ nas públicas.

Quando a análise é focada nas instituições de educação superior (IES), esse cenário não se altera, já que possuímos 2.069 IES privadas, sendo a maioria na categoria de Faculdades, enquanto o setor público registra 295 IES (BRASIL, 2015). Esses dados revelam que 
$88 \%$ das nossas IES são privadas, enquanto apenas $12 \%$ são públicas, demonstrando o alto índice de privatização da educação superior brasileira, mesmo levando-se em conta as recentes políticas de ampliação e interiorização da rede pública implementadas no Governo Lula.

Em termos de organização acadêmica, as faculdades totalizam 1.980 estabelecimentos, correspondendo a $85 \%$ das IES, enquanto as universidades e os centros universitários correspondem a $8 \%$ e $7 \%$, respectivamente. Nesse sentido, podemos observar que o nosso sistema de educação superior está constituído em sua maioria de faculdades privadas, com viés mercantil, de qualidade questionável, que se dedicam fundamentalmente ao ensino e não realizam pesquisa nem extensão de forma sistemática. Nesse sentido, o Brasil continua sendo um dos países mais privatizados e mercantilizados da América Latina no que se refere ao ensino superior.

O processo de privatização da educação superior brasileira está evidenciado na análise de Pinto (2004, p. 729-730):

\begin{abstract}
Em especial nos últimos 40 anos, o país apresentou uma grande expansão nas matrículas de graduação [...] de tal forma que de 1960 a 2002 as matrículas cresceram 37 vezes. Cabe ressaltar, contudo, que este aumento se deu de forma distinta entre as redes pública e privada. Assim é que, enquanto, no mesmo período, as matrículas na rede privada cresceram 59 vezes, na rede pública o aumento foi de 20 vezes. O resultado deste processo é que se em 1960 o setor privado respondia por $44 \%$ das matrículas de graduação, em 2002, essa participação passou para $70 \%$, tornando o Brasil um dos países com mais elevado grau de privatização desse nível de ensino. Basta dizer que a participação do setor privado nas matrículas no Brasil é quase três vezes maior que a média dos países da Organização para Cooperação e Desenvolvimento Econômico (OCDE).
\end{abstract}

Mais recentemente, Ristoff (2013, p. 3) apresentou um novo panorama da educação superior brasileira através do estudo "Vinte e um anos de educação superior: expansão e democratização", que foi produzido a partir dos Censos da Educação Superior de 1991 a 2011. Os dados apresentados reforçam que a educação superior concentra-se fundamental-mente no setor privado. Ristoff relata que o crescimento das instituições privadas deu-se principalmente após a Lei de Diretrizes e Bases no 9394 de 1996 e que uma parcela significativa delas compõe-se de faculdades isoladas que atendem até mil matrículas.

As matrículas cresceram 330\%, de 1991 a 2011, mas apesar dessa expansão o Brasil ainda não conseguiu cumprir com a meta de pelo menos $30 \%$ de matrículas na faixa etária de 18 a 24 anos, proposta no primeiro Plano Nacional de Educação (2001- 2010). Esse mesmo Plano propõe "ampliar a oferta de ensino público de modo a assegurar uma proporção nunca inferior a 40\% do total das vagas" na educação superior (BRASIL, 2001).

O novo Plano Nacional de Educação, aprovado pela Lei $n^{\circ} 13.005$, de 25 de junho de 2014 (BRASIL, 2014), com vigência de dez anos a partir da data da publicação dessa Lei, na sua meta 12, prevê: "elevar a taxa bruta de matrícula na educação superior para $50 \%$ e a taxa líquida para 33\% da população de 18 a 24 anos, assegurada a qualidade da oferta e expansão para, pelo menos, $40 \%$ das novas matrículas no segmento público". Para tal, propõe 21 estratégicas para o cumprimento dessa meta, entre as quais, destacam-se:

- ampliar as políticas de inclusão e de assistência estudantil dirigidas aos (às) estudantes de instituições públicas, bolsistas de instituições privadas de educação superior e beneficiários do Fundo de Financiamento Estudantil - FIES, de que trata a Lei $\mathrm{n}^{\mathrm{o}} 10.260$, de 12 de julho de 2001, na educação superior, de modo a reduzir as desigualdades étnico-raciais e ampliar as ta- 
xas de acesso e permanência na educação superior de estudantes egressos da escola pública, afrodescendentes e indígenas e de estudantes com deficiência, transtornos globais do desenvolvimento e altas habilidades ou superdotação, de forma a apoiar seu sucesso acadêmico (12.5); - ampliar a participação proporcional de grupos historicamente desfavorecidos na educação superior, inclusive mediante a adoção de políticas afirmativas, na forma da lei (12.9).

Para Gomes e Moraes (2012, p. 174), o sistema de massa corresponde ao atendimento entre $16 \%$ e $50 \%$ do grupo etário de 18 a 24 anos, estando plenamente consolidado quando atinge mais de $30 \%$ de jovens matriculados nesta faixa etária. O sistema de elite, segundo esta classificação, atende até $15 \%$ do grupo etário definido e, no sistema de acesso universal, o atendimento ultrapassa 50\%. Os dados para a educação superior brasileira, segundo o Censo de 2012 (BRASIL, 2012) eram: 27,8\% de matrículas totais (taxa de escolarização bruta) e 14,6\% de matrículas na faixa etária de 18 e 24 anos (taxa de escolarização líquida). Assim, mesmo com os esforços e medidas legais para massificar e democratizar a educação superior a partir do Governo Lula, ainda continuamos na transição de um sistema de elite para um sistema de massa, com forte presença do setor privado em termos de instituições e matrículas nesse nível de ensino.

Em relação à permanência dos alunos nas IES, Ristoff constatou que dos 447.929 ingressantes na educação superior em 1991, apenas 245.887, ou seja, 55\% graduaram-se quatro anos mais tarde e que "gerações mais recentes vêm enfrentando mais dificuldades para se graduarem, chegando em 2011 com taxa de sucesso de apenas 44\%" (2013, p. 4). Ao analisar a questão dos concluintes, o autor demonstra que houve uma queda significativa no ritmo de crescimento dos concluintes no período de 2006 a 2011, comparando-se com os seis anos precedentes. Não obstante os programas de expansão das universidades federais e da rede de institutos federais de educação tecnológica, o setor privado ainda responde por $79 \%$ dos concluintes dos cursos de graduação.

Diante das questões abordadas, pode-se afirmar que a educação superior brasileira, a partir da Reforma de 1968, sofreu um esmagamento de sua principal atribuição, que é a de oferecer o ensino superior de modo democrático e igualitário, com qualidade. Na verdade, ela permitiu a expansão do setor privado e não criou a "verdadeira universidade", com a sua proposta de indissociabilidade entre ensino, pesquisa e extensão, então alardeada. Paula (2011, p. 59-60) aponta que a Lei 5.540/1968 trouxe alterações significativas na estrutura organizacional da educação superior brasileira, entre elas: a instituição do vestibular unificado, do ciclo básico ou primeiro ciclo geral, dos cursos de curta duração, do regime de créditos e da matrícula por disciplinas, todas estas medidas visando uma maior racionalização para as universidades; o fim da cátedra e a instituição do sistema departamental; a criação da carreira docente aberta e do regime de dedicação exclusiva; a expansão do ensino superior, por intermédio da ampliação do número de vagas nas universidades públicas e da proliferação de instituições privadas; a ideia moderna de extensão universitária; a ênfase nas dimensões técnica e administrativa do processo de reformulação da educação superior, no sentido da despolitização da mesma.

A reforma dos anos 1990, com forte influência das políticas neoliberais, acirrou o processo de privatização e diferenciação da educação superior no Brasil, com respaldo da nova Lei de Diretrizes e Bases da Educação, n. 9.394/1996. Acentuaram-se o aligeiramento e a fragmentação da formação de nível superior, por meio dos cursos de curta duração, cursos se- 
qüenciais, cursos para tecnólogos, cursos de educação a distância, entre outros. Os governos de Fernando Henrique Cardoso (1995-2002) intensificaram as políticas neoliberais na educação superior, desmontando o setor público e permitindo a proliferação indiscriminada de IES e cursos privados, sem controle de qualidade, apesar das políticas de avaliação da educação superior que se multiplicaram nesse período. Ou seja, o Estado avaliador não cumpriu o seu papel de controlar a qualidade dos cursos ofertados no nível superior, em especial no setor privado.

Nesse sentido, Cunha (2004) reforça que as instituições privadas de ensino superior se multiplicaram em número e cresceram em tamanho em decorrência da demanda por vagas e pelo freio na velocidade de expansão das redes públicas de ensino. Vale observar que esse panorama deve-se, principalmente, às normas governamentais, facilitadoras do processo de surgimento e multiplicação de novas instituições privadas, refletindo a diversificação das instituições de educação superior no Brasil.

Nesse cenário, prevalece a concepção da educação-mercadoria que torna-se acessível "aos clientes" através do mecanismo de compra, contrapondo-se à educação como bem público, dever de Estado e direito do cidadão, visando o alcance de uma sociedade mais justa e democrática. Somente a partir da concepção de educação como bem público, é "que faz sentido falar em democratização do acesso e garantia de permanência dos estudantes em cursos superiores com qualidade científica e social" (DIAS SOBRINHO, 2010, p. 1.225).

A concepção de democratização de educação superior que embasa este artigo é construída sobre quatro dimensões: a do acesso/ingresso, a da permanência/conclusão, a da formação com qualidade e a da inclusão das camadas subalternizadas socialmente na educação superior, como nos esclarecem Paula e Silva (2012, p. 7):

Partimos do princípio de que a ênfase na política de expansão e massificação não esgota o projeto de democratização da educação superior. Esse processo só se completará se tivermos igual proporção de crescimento na taxa de concluintes, com integração crescente das camadas marginalizadas socialmente, sobretudo dos estudantes de baixa renda. É necessário visar com igual ênfase o final do processo: a conclusão, com êxito, dos cursos superiores, integrando nesses índices as camadas subalternizadas da população, com garantia de qualidade na formação. A vigilância constante sobre a qualidade dos cursos de graduação, as taxas de conclusão e o perfil socioeconômico dos concluintes e dos que evadem nos parece essencial, não apenas para atestar ou não o sucesso do processo como para produzir feedbacks sobre as políticas adotadas.

\section{Políticas de inclusão na educação superior brasileira: problemas e limites}

A expansão e a massificação da educação superior representam o primeiro passo no sentido da democratização do sistema, porém não são suficientes para a inclusão, de fato, das camadas social e historicamente excluídas. Ezcurra (2011) nos mostra em suas análises que tem havido, na América Latina como um todo e o caso brasileiro não é exceção a esta regra, um fenômeno de massificação da educação superior que tem expulsado do sistema as camadas socialmente desfavorecidas. Estas têm sido vítimas de uma tendência estrutural do sistema - "una inclusión excluyente, según classes y sectores sociales, socialmente condicionada (p. 62)" - que se traduz na dificuldade de acesso e, sobretudo, de permanência dos estudantes das classes populares. Ou seja, os elevados índices de evasão ao longo do percurso universitário continuam atingindo em maior proporção os estudantes provenientes das classes populares. 
Apesar das políticas voltadas para a "democratização" do ensino superior a partir de 2003 (Governos Lula e Dilma), como o Programa Universidade para Todos (PROUNI), aprovado pela Lei n. 11.096, de 13/01/2005, que facilita o acesso de estudantes de baixa renda nas IES privadas; o Programa de Apoio a Planos de Reestruturação e Expansão das Universidades Federais - REUNI, instituído pelo Decreto $n^{\circ}$ 6.096, de 24 de abril de 2007, que tem promovido a expansão e interiorização das universidades federais; as políticas de ação afirmativa, consolidadas pela Lei $\mathrm{n}^{\circ} 12.711$, de 29/08/2012 (cotas reservadas a estudantes provenientes da escola pública nas universidades federais, priorizando os alunos de baixa renda e o recorte étnico-racial), entre outras medidas, a inclusão dos segmentos marginalizados socialmente ainda não se concretizou no Brasil, em especial nos cursos de alta demanda, que conferem maior possibilidade de mobilidade social.

Essas iniciativas enfrentam barreiras relacionadas à permanência desses estudantes no sistema, pois eles enfrentam dificuldades materiais e acadêmicas, relativas à sua trajetória na educação básica e ao seu capital econômico, social e cultural. O aumento de vagas e a possibilidade de ingresso ampliado, em alguns casos, assim como a reserva de vagas a segmentos mais vulneráveis, em outros, não são acompanhados satisfatoriamente por políticas que garantam a conclusão dos cursos de graduação. Isto faz com que muitos desses alunos adentrem as portas da educação superior e saiam antes de se formarem, ocorrendo o fenômeno da inclusão excludente analisado por Ezcurra (2011, p. 62): a porta aberta na educação superior para os segmentos desfavorecidos socialmente na verdade trata-se de uma porta giratória.

No caso brasileiro, podemos dizer que, mais do que uma reprodução das desigualdades sociais pela educação superior, os dados nos mostram que há uma hipertrofia destas desigualdades sociais, sobretudo nos cursos de alta demanda/ maior prestígio social. Segundo Ristoff (2011, p. 209-210):

\footnotetext{
A oportunidade de acesso para estudantes pobres é um bom exemplo. Estudantes com renda familiar de até 3 salários mínimos, que na população brasileira representam 50\%, na Enfermagem e Educação Física - cursos com percentuais mais próximos da realidade - representam apenas cerca de $30 \%$. Esta distorção se torna mais gritante na Odontologia e na Medicina, onde os $50 \%$ passam a ser apenas $10,5 \%$ e $8,8 \%$, respectivamente. Ou seja, como ressaltam os casos da Enfermagem e da Educação Física, mesmo o que no campus mais se aproxima da realidade está profundamente distorcido, e para pior.
}

Ainda segundo Ristoff, quando se olha a questão pelo viés dos mais ricos (mais de dez salários mínimos de renda familiar), percebe-se que uma pequena minoria na sociedade tornase uma grande maioria no campus. Na sociedade, este grupo representa 11,8\%. Nos cursos de Odontologia e Medicina, no entanto, os 11,8\% de ricos tornam-se 52\% e 67\%, respectivamente.

Interessa especialmente a este artigo problematizar os efeitos das políticas de inclusão voltadas para as universidades federais, tais como REUNI, PNAES e Política de Cotas, implementadas a partir do governo Lula, pois as políticas de democratização devem priorizar o setor público, que prima pela qualidade da formação, realizando pesquisa e extensão de forma sistemática.

O REUNI tem como objetivo, de acordo com seu artigo 1: "criar condições para a ampliação do acesso e permanência na educação superior, no nível de graduação, pelo melhor 
aproveitamento da estrutura física e de recursos humanos existentes nas universidades federais".

O REUNI também tem como objetivos a elevação da taxa média de conclusão dos cursos presenciais de graduação para noventa por cento e da relação de alunos de graduação por professor para dezoito, num prazo de cinco anos (art. 1, \& 1), praticamente dobrando a relação de alunos por professores em cursos presenciais de graduação.

O REUNI possui como diretrizes (art. 2) a redução das taxas de evasão, a ocupação de vagas ociosas e o aumento de vagas de ingresso, especialmente no período noturno; a ampliação de políticas de inclusão e assistência estudantil; a articulação da pós-graduação com a graduação e da educação superior com a educação básica.

Como parte do REUNI, houve um processo de expansão das universidades federais por todo o Brasil, com a criação de inúmeros campi no interior dos Estados onde estão situadas estas universidades, favorecendo um processo de interiorização do ensino superior.

Todavia, o REUNI tem sido alvo de duras críticas no meio acadêmico e estudantil, pois existe a preocupação de que o processo de ampliação de vagas nas universidades públicas se dê com o sacrifício da qualidade, transformando estas instituições em "escolões" de terceiro grau, o que poderia comprometer a excelência da formação universitária, da pesquisa e da extensão.

Pesquisa realizada pela Associação Nacional dos Dirigentes das Instituições Federais de Ensino Superior (ANDIFES) sobre o perfil dos estudantes das universidades federais, publicada em 2011, mostra que 44\% pertencem às classes C, D e E (ANDIFES; FONAPRACE, 2011). A preocupação por políticas públicas que incluam o "jovem pobre" tem se estendido à questão racial. Nessa direção, a referida pesquisa (2011, p. 23) aponta que os estudantes brancos perfazem um total de 54\% nas Instituições Federais de Ensino Superior (IFES), sendo majoritariamente da classe A, ao passo que os pretos e pardos totalizam 40,8\%, concentrando-se nas classes $\mathrm{C}, \mathrm{D}$ e $\mathrm{E}$.

No sentido da democratização da educação superior, percebe-se que à expansão de vagas observada nas universidades federais são acrescidas iniciativas para incrementar o ingresso da população de baixa renda e de segmentos discriminados. Nesse bojo, tem crescido a preocupação com a permanência dos estudantes, e, por consequência, com a assistência estudantil. Alguns marcos regulatórios podem ser citados nessa direção, a partir dos anos 2000:

- Lei n ${ }^{\circ}$ 10.172, de 10/01/2001: o Plano Nacional de Educação (PNE) propõe "estimular a adoção, pelas instituições públicas, de programas de assistência estudantil, tais como bolsa-trabalho ou outros destinados a apoiar os estudantes carentes que demonstrem bom desempenho acadêmico" (item 34). Porém, o financiamento público não se viabilizou para cumprir a contento objetivos e metas do PNE;

- Lei n· 10.861, de 14/04/2004: o Sistema Nacional de Avaliação da Educação Superior (SINAES) considera, para fins de avaliação das IES, a responsabilidade social da instituição com relação à inclusão social e às políticas de atendimento a estudantes e egressos (IX dimensão);

- Plano de Desenvolvimento da Educação (PDE), aprovado em 2007: o Ministério da Educação (MEC) estabelece um plano que conjuga programas para a educação básica e a educação superior, mediante leis, decretos, resoluções e portarias. Nesse âmbito, institui o REUNI e fortalece o Programa Universidade para Todos (PROUNI) e o Fundo de Financia- 
mento Estudantil (FIES). Presente está a ideia de inclusão social, a fim de contemplar "os excluídos pelo filtro de natureza econômica";

- Portaria Normativa no 39, de 12/12/2007: aprova o Programa Nacional de Assistência Estudantil (PNAES), que se destina a estudantes de baixa renda matriculados em cursos de graduação presenciais nas IFES, selecionados por critérios socioeconômicos e outros definidos pela instituição formadora. $\mathrm{O}$ art. $3^{\circ}$ da Portaria define que:

[...] as ações de assistência estudantil devem considerar a necessidade de viabilizar a igualdade de oportunidades, contribuir para a melhoria do desempenho acadêmico e agir, preventivamente, nas situações de repetência e evasão decorrentes da insuficiência de condições financeiras.

O PNAES foi institucionalizado pelo Decreto 7.234, de 19 de julho de 2010, assinado pelo então Presidente Luiz Inácio Lula da Silva e pelo então Ministro da Educação Fernando Haddad. O PNAES oferece assistência à moradia estudantil, alimentação, transporte, à saúde, inclusão digital, cultura, esporte, creche e apoio pedagógico. As ações são executadas pela própria instituição de ensino, que deve acompanhar e avaliar o desenvolvimento do programa.

A aprovação do PNAES pode ser considerada um marco na história da assistência estudantil no Brasil. A sua importância reside em que o governo federal compromete-se, por lei, com o repasse de recursos às instituições federais de ensino superior, aliviando-as da responsabilidade de criar fundos a partir de recursos próprios para realizar a assistência estudantil, ou seja, esta se materializa como política pública.

Outra iniciativa afeta à permanência refere-se à Portaria 389, de 09/05/2013, que cria o Programa de Bolsa Permanência. O Programa expressa a intenção de contribuir para a permanência e diplomação dos estudantes de graduação das IFES (em especial indígenas e quilombolas) em situação de vulnerabilidade socioeconômica, reduzir problemas provocados por evasão e promover ações complementares com vistas ao desempenho acadêmico. Define que, entre outros critérios, o candidato à bolsa possua renda familiar per capita não superior a 1,5 salário mínimo e esteja matriculado em curso com carga horária média superior ou igual a 5 horas diárias.

A Lei $n^{\circ}$ 12.711, de 29/08/2012 (BRASIL,2012), aprovada já no Governo Dilma, depois de amplo debate na mídia e nas instituições de educação superior durante anos, dispõe sobre o ingresso nas universidades federais e nas instituições federais de ensino técnico de nível médio e passou a vigorar no processo seletivo de 2013. A Lei trata da reserva de vagas em cada concurso seletivo para cursos de graduação, por curso e turno, de no mínimo 50\% para estudantes que tenham cursado integralmente o ensino médio em escolas públicas. Assegura que $50 \%$ dessas vagas sejam reservadas a estudantes oriundos de famílias com renda igual ou inferior a 1,5 salário mínimo per capita (art. 1o). Registra, ainda, que as vagas de que trata o art. 1o da Lei sejam preenchidas, por curso e turno, por autodeclarados pretos, pardos e indígenas, em proporção no mínimo igual à população de pretos, pardos e indígenas da unidade da Federação onde está instalada a instituição, segundo o último censo do Instituto Brasileiro de Geografia e Estatística (art. 3o).

O resgate dos documentos e leis citados revela que as políticas de inclusão na educação superior brasileira levam em conta a renda e a condição étnico-racial dos estudantes, visando minimizar as desigualdades sociais presentes nos campi universitários. 
Em texto recente, Ristoff (2014) discute até que ponto as políticas de "democratização" implementadas nos governos Lula e Dilma, tais como Programa Universidade para Todos (PROUNI), Programa de Estímulo à Reestruturação e ao Fortalecimento das Instituições de Ensino Superior (PROIES), o novo Fundo de Financiamento ao Estudante do Ensino Superior (FIES), o Sistema de Seleção Unificada (SiSu), o Programa de Apoio a Planos de Reestruturação e Expansão das Universidades Federais (REUNI), a Lei das Cotas nas Instituições Federais, a criação dos Institutos Federais de Educação, de novas universidades federais, a política de interiorização das universidades federais, o Plano Nacional de Assistência Estudantil (PNAES) começam a alterar o perfil socioeconômico do estudante de graduação. O autor procura demonstrar, com base em informações extraídas do questionário socioeconômico do Exame Nacional de Desempenho do Estudante (ENADE), que essas políticas, aplicadas aos setores privado e público da educação superior, começam a produzir mudanças no perfil do estudante que ingressa no ensino superior brasileiro.

Ristoff mostra como ainda existem diferenças gritantes entre os cursos de baixa demanda/baixo prestígio social e os cursos de alta demanda/alto prestígio social, no que se refere à cor do estudante, à renda mensal da família do estudante, à sua origem escolar (escola privada ou escola pública) e à escolaridade dos pais, apesar das políticas implementadas nos últimos governos.

Embora tenha havido uma adesão em massa das universidades federais e dos institutos federais à Lei de Cotas (12.712/2012), os dados do ENADE evidenciam de forma contundente a distância existente entre o que preconiza essa Lei (50\%), o que representa efetivamente a escola pública de ensino médio (87\%) e o que ocorre em alguns cursos de graduação do país. Segundo Ristoff (2014, p. 745):

\footnotetext{
Mais distantes dos 50\% exigidos pela Lei estão os cursos de Medicina e de Odontologia. Direito se aproxima dos $50 \%$ exigidos pela Lei, mas percebe-se que ainda está muito distante da representação efetiva do Ensino Médio público [...] Também cursos como História, Biblioteconomia, Pedagogia e as licenciaturas em geral, que já superam o exigido pela Lei, estão ainda a considerável distância da representação percentual do Ensino Médio público. Efetivamente, nenhum curso de graduação atinge a paridade e somente 6 dos 47 cursos sob análise têm, no segundo ciclo do ENADE, mais de $70 \%$ de estudantes oriundos da escola pública.
}

Cabe ressaltar, ainda, segundo essa pesquisa, que as distorções ainda existentes tornam-se mais agudas quando observamos as vagas reservadas pelas Instituições Federais de Educação Superior (IFES) para pretos, pardos e indígenas (PPIs). Das 283.445 vagas ofertadas pelas IFES em 2014/1, 70.861 (25\%) foram reservadas para cotistas e a metade destas para PPIs. É bom registrar que este grupo representa $51 \%$ da população brasileira, e que, portanto, em condições de igualdade de representação, deveria estar representado nas IFES com 144.556 vagas (RISTOFF, 2014, p. 745).

Contudo, o autor ressalta que, em função das políticas de inclusão na educação superior implementadas pelos governos Lula e Dilma, "em todos os cursos um número cada vez menor de estudantes ricos ingressa na educação superior, mesmo em cursos de alta demanda", como Medicina, Odontologia, Direito e Psicologia (p. 736). Coloca em relevo na sua análise um processo crescente de mudança do perfil dos ingressantes e por consequência de "democratização" do ensino superior no Brasil. 
Porém, o acesso não garante a inclusão de fato na educação superior, pois este deve ser acompanhado de políticas de permanência que permitam a conclusão dos cursos pelos estudantes de baixa renda e pelas minorias étnicas, que historicamente têm sido excluídos do ensino superior, sobretudo dos cursos de alta demanda/ elevado prestígio social. Em correlação com este problema, a educação superior brasileira apresenta elevadas taxas de evasão e pequenas taxas de conclusão em muitos cursos de graduação.

Em conformidade com essa tendência, a Tabela 1 mostra a expansão nas universidades federais brasileiras no período de 2000 a 2015, indicando a evolução crescente de vagas e de ingressantes, com diminuição da taxa de concluintes a partir de 2008, paradoxalmente no período em que foram aprovados o REUNI e o PNAES.

Tabela 1 - Vagas, ingressos e concluintes em cursos de graduação presenciais em universidades federais. Brasil - 2000-2015

\begin{tabular}{|c|c|c|c|c|}
\hline Ano & Vagas & Ingressos & Concluintes & $\begin{array}{c}\text { Taxa de } \\
\text { Concluintes }\end{array}$ \\
\hline 2000 & 112.826 & 110.173 & 56.070 & 67,62 \\
\hline 2001 & 110.928 & 108.827 & 62.385 & 73,07 \\
\hline 2002 & 113.263 & 111.841 & 68.001 & 75,28 \\
\hline 2003 & 109.184 & 108.466 & 78.454 & 71,21 \\
\hline 2004 & 109.802 & 108.953 & 82.761 & 76,05 \\
\hline 2005 & 116.348 & 114.833 & 83.020 & 74,23 \\
\hline 2006 & 132.203 & 130.285 & 80.095 & 73,84 \\
\hline 2007 & 139.875 & 136.834 & 84.674 & 77,72 \\
\hline 2008 & 150.869 & 145.062 & 79.764 & 69,46 \\
\hline 2009 & 186.984 & 184.708 & 86.348 & 66,28 \\
\hline 2010 & 218.152 & 222.126 & 88.106 & 64,39 \\
\hline 2011 & 231.530 & 224.950 & 92.429 & 63,72 \\
\hline 2012 & 239.942 & 238.594 & 89.709 & 48,57 \\
\hline 2013 & 245.933 & 233.693 & 99.343 & 42,51 \\
\hline 2014 & 251.748 & 233.667 & 108.862 & 46,58 \\
\hline 2015 & 260.227 & 236.593 & 112.667 & 47,62 \\
\hline
\end{tabular}

Tabela elaborada pela autora com base nas sinopses estatísticas do MEC/INEP de 2000 a 2015

Um indicador importante para avaliar a permanência refere-se à taxa de concluintes, calculada a partir do número de concluintes, transcorridos quatro anos após o seu ingresso. Como mostra a Tabela 1, entre 2000 e 2015, em números absolutos, os concluintes evoluíram positivamente, ainda que de forma tímida e oscilante. $\mathrm{O}$ crescimento dos concluintes acontece em patamares inferiores à expansão de vagas e de ingressantes, acarretando em taxas de diplomação decrescentes, sobretudo após 2008.

Nota-se que, ao mesmo tempo em que crescem vagas e ingressos, fomentados pelo Programa de Apoio a Planos de Reestruturação e Expansão das Universidades Federais (REUNI), a partir de 2008 houve uma queda significativa no ritmo de crescimento dos concluintes. O emblemático é que, mesmo nos anos seguintes à implantação do Plano Nacional 
de Assistência Estudantil (PNAES), em 2007, não se observa um impacto significativo na taxa de conclusão dos cursos de graduação, mas, ao contrário, o seu declínio.

Pesquisas têm indicado como impactantes nos índices de evasão dos cursos de graduação o papel do professor universitário e a percepção de não pertencimento dos estudantes em relação ao ambiente universitário (BARDAGI; HUTZ, 2012). É destacada, ainda, a influência do formato seletivo do Sistema de Seleção Unificado (SiSU), que, dadas as suas características, tenderia a potencializar incertezas na continuidade dos estudos (SILVA; VELOSO, 2013). Por sua vez, Néres et al. (2010, p. 124), num estudo de caso em uma universidade federal, concluem que o estudante ingressante "[...] depende de um acolhimento por parte da mesma", e que os fatores que contribuem para a não permanência na educação superior dos estudantes de origem popular ligam-se não apenas às condições econômicas, mas às dificuldades para acompanhar os conteúdos de ensino, em razão de deficiências na formação escolar antecedente. Já Paula e Vargas (2013), ao focalizarem os ingressantes e concluintes das universidades federais, mostram que se perde cerca de um terço dos alunos no percurso universitário; nesse bojo, para as autoras, reside a realidade do estudante-trabalhador e do trabalhadorestudante, que enfrentam dificuldades extremas para conciliar as atividades laborais e educacionais. O enfrentamento da problemática (trabalho e estudo), do ponto de vista da implementação de políticas públicas e da legislação brasileira, a seu ver, não tem se apresentado a contento.

Ou seja, o ingresso não garante a permanência na educação superior, sobretudo dos estudantes de baixa renda e das minorias étnicas, que enfrentam dificuldades de ordem econômica, pedagógica e simbólico-subjetiva.

Os problemas financeiros e a necessidade de trabalhar fazem com que muitos estudantes abandonem os cursos das universidades federais, em especial os de alta demanda, como Medicina, Odontologia, Engenharias, pois estes cursos requerem disponibilidade dos estudantes em horário integral, ocupando, às vezes, todo o dia ou sendo oferecidos em horários variados, que impossibilitam a conciliação com o mundo do trabalho. Assim, as universidades federais estão estruturadas para contemplar o estudante proveniente das classes dominantes, que não necessita trabalhar e não o estudante-trabalhador e o trabalhador-estudante. Este fato se agrava, se levarmos em conta que a demanda por bolsas é muito maior do que a oferta.

As dificuldades de ordem pedagógica relacionam-se ao fato dos estudantes de baixa renda possuírem menor capital cultural e social, muitos vindos das escolas públicas de nível médio, com infra-estrutura deficitária e menor qualidade em relação às escolas de elite, não estando preparados para enfrentar os desafios dos cursos universitários.

As dificuldades de ordem simbólico-subjetiva referem-se a uma inclusão excludente efetuada no interior das universidades federais, que continuando elitistas, não estão voltadas para receber uma clientela de origem popular, no tocante aos currículos pouco flexíveis, à relação professor-aluno, à falta de acolhimento para esse novo perfil de estudante que tem ingressado pela expansão de vagas e pelas políticas de ação afirmativa. Ou seja, o mesmo espaço considerado de inclusão pode ser considerado de exclusão, pois discrimina e expulsa os estudantes que são diferentes do padrão elitizado e culto ainda requerido pelas universidades federais.

Deserdados ou excluídos no interior das universidades federais (BOURDIEU; CHAMPAGNE, 1998), aos pobres e às minorias étnicas são reservados os cursos de menor 
prestígio social ou quando ingressam nos cursos de maior prestígio social, correm o risco descrito por Ezcurra (2011) de adentrar a universidade através de uma porta giratória, não permanecendo.

Nesse sentido, pode-se dizer que há uma "seleção" imposta aos "sujeitos envolvidos na inclusão ou exclusão da universidade brasileira", que pode ser interpretada "como um instrumento de controle social", onde o "lugar possível para cada um é pré-determinado". Ou seja, as políticas de inclusão na educação superior não têm alterado "a tradicional ordem da estratificação social" (PAULA; HOURI; CRUZ, 2015, p. 217).

Sob esta perspectiva de análise, inclusão e exclusão, acesso/permanência/evasão devem ser vistos em conjunto e não separadamente. Como pensar na inclusão sem pensar na exclusão? Como pensar no acesso e na permanência sem pensar na evasão?

\section{Considerações finais}

É preciso desnaturalizar os discursos e práticas consagrados sobre inclusão, buscando modos alternativos de resistências e proposições. Algumas questões que se colocam a partir dessa perspectiva são: a tentativa de incluir novos perfis de alunos na educação superior em um modelo de universidade que, em grande medida, não se alterou, tem contribuído para as elevadas taxas de evasão nos cursos de graduação? As políticas de inclusão que têm sido implementadas pelas instituições de educação superior, em especial as universidades federais, têm acolhido estes novos estudantes de forma satisfatória, do ponto de vista material, acadêmico, pedagógico, das relações humanas e existenciais? Esse modelo de inclusão tem respeitado as diferenças individuais, de classes sociais, cor? Que mudanças as universidades federais devem promover para incluir, de fato, os segmentos historicamente excluídos? Nesse sentido, segundo Provin (2013, p. 100):

\footnotetext{
Entender a inclusão como um conceito mais amplo, que considera diferentes grupos de sujeitos e no qual as diferenças têm espaços para falar de si, pode ser uma possibilidade de olhar de outra forma para os processos e práticas de in/exclusão que ocorrem na Contemporaneidade [...] O processo de in/exclusão não se dá apenas pelo fato de os sujeitos não estarem no mesmo espaço que outros, mas por estarem no mesmo espaço e, por vezes, não serem considerados como alguém que faz parte dele.
}

A política assistencialista que tem sido implementada pelas universidades federais brasileiras baseia-se sobretudo no suporte financeiro aos estudantes carentes, ainda muito aquém da demanda, deixando em plano secundário as suas necessidades de ordem acadêmica, simbólica e existencial, relacionadas a sentimentos de não pertencimento a um ambiente ainda elitista e pouco propício à inclusão.

O processo de expansão e massificação da educação superior brasileira, com o incremento de ingressos e matrículas, nas últimas décadas, não tem significado necessariamente a inclusão social das camadas historicamente excluídas, pois pesquisas citadas indicam que os estudantes das classes sociais subalternizadas e as minorias étnicas têm menores chances de acesso e permanência no ensino superior, em especial nos cursos de alta demanda / prestígio social, que possibilitam maior mobilidade social. Para isto, as políticas de ação afirmativa, expansão e interiorização com qualidade da rede pública, assim como de permanência e assis- 
tência estudantil devem ser intensificadas, para incluir os setores excluídos socialmente nas universidades, em especial as públicas.

Além disso, as universidades federais devem se reestruturar internamente, abrir-se para as inovações pedagógicas, implodir sistemas de poder enrijecidos, romper com preconceitos, de forma a tornarem-se aptas para receber esta nova parcela da população historicamente excluída do ensino superior.

Os elevados índices de evasão dos estudantes nos cursos de graduação e a correlata diminuição da taxa de concluintes nas universidades federais, nos últimos anos, como descrito anteriormente, apesar do incremento das políticas de acesso e assistência estudantil voltadas para os setores desfavorecidos socialmente e para as minorias étnicas, fazem com que o ciclo de democratização não se complete de forma satisfatória.

A inclusão dos setores subalternizados e das minorias étnicas no ensino superior, sobretudo nos cursos mais prestigiados socialmente, é condição indispensável para a diminuição das profundas desigualdades sociais existentes no Brasil.

\section{Referências}

ANDIFES/FONAPRACE - Fórum Nacional de Pró-Reitores de Assuntos Comunitários e Estudantis. Perfil socioeconômico e cultural dos estudantes de graduação das universidades federais brasileiras. Brasília: ANDIFES/FONAPRACE, 2011.

BARDAGI, Marucia Patta; HUTZ, Claudio Simon. Rotina acadêmica e relação com colegas e professores: impacto na evasão universitária. Psico, Porto Alegre, v. 43, n. 2, p. 174-184, abr./jun. 2012.

BOURDIEU, Pierre; CHAMPAGNE, Patrick. Os excluídos do interior. In: NOGUEIRA, Maria Alice; CATANI, Afrânio (Orgs.). Escritos de educação. Petrópolis: Vozes, 1998. p. 217-227.

BRASIL. Decreto n. 6.096 de 24/ 04/2007. Institui o Programa de Apoio a Planos de Reestruturação e Expansão das Universidades Federais - REUNI. Diário Oficial da União, Brasília, 25 abr. 2007.

BRASIL. Decreto n. 7.234 de 19/ 07/2010. Dispõe sobre o Programa Nacional de Assistência Estudantil - PNAES. Diário Oficial da União, Brasília, 20 jul. 2010.

BRASIL. Lei n. 10.172 de 09/01/2001. Aprova o Plano Nacional de Educação - PNE e dá outras providências. Diário Oficial da União, Brasília, 10 jan. 2001.

BRASIL. Lei n. 10.861 de 14/04/2004. Institui o Sistema Nacional de Avaliação da Educação Superior - SINAES e dá outras providências. Diário Oficial da União, Brasília, 15 abr. 2004.

BRASIL. Lei n. 12.711 de 29/08/2012. Dispõe sobre o ingresso nas universidades federais e nas instituições federais de ensino técnico de nível médio e dá outras providências. Diário Oficial da União, Brasília, 30 ago. 2012.

BRASIL. Lei n. 13.005 de 25/06/2014. Aprova o Plano Nacional de Educação - PNE e dá outras providências. Diário Oficial da União, Brasília, 26 jun. 2014. 
BRASIL. Portaria Normativa n. 39 de 12/12/2007. Institui o Programa Nacional de Assistência Estudantil - PNAES. Diário Oficial da União, Brasília, 13 dez. 2007.

BRASIL. Portaria n. 389, de 09/05/2013. Cria o Programa de Bolsa Permanência e dá outras providências. Diário Oficial da União, Brasília, 10 maio 2013.

BRASIL. MEC/ INEP. Resumo técnico. Censo da educação superior 2012. Brasília:DF. Disponível em: < http://www.inep.gov.br>. Acesso em: mar. 2016.

BRASIL. MEC/INEP. Resumo Técnico. Censo da educação superior 2015. Brasília: DF. Disponível em:< http://www.inep.gov.br>. Acesso em: fev. 2017.

BRASIL. MEC/INEP. Sinopses estatísticas. Censo da educação superior. 2000 a 2015. Brasília: DF. Disponível em: < http://www.inep.gov.br>. Acesso em: fev. 2017.

CUNHA, Luiz Antônio. Desenvolvimento desigual e combinado no ensino superior - Estado e Mercado. Educação \& Sociedade, Campinas, v. 25, n. 88, p.795-817, Especial out. 2004. Disponível em: <http://www.scielo.br/pdf/es/v25n88/a08v2588.pdf>. Acesso em: 15 fev. 2016.

DIAS SOBRINHO, José. Democratização, qualidade e crise da educação superior: faces da exclusão e limites da inclusão. Educação \& Sociedade, Campinas, v. 31, n. 113, p. 1223 1245, out.- dez. 2010. Disponível em: <http://www.scielo.br/pdf/es/v31n113/10.pdf〉. Acesso em: 5 maio 2016.

EZCURRA, Ana María. Masificación y enseñanza superior: una inclusión excluyente. Algunas hipótesis y conceptos clave. In: FERNÁNDEZ LAMARRA, Norberto; PAULA, Maria de Fátima Costa de (Orgs.). La democratización de la educación superior en América Latina. Límites y posibilidades. Saenz Peña: EDUNTREF, 2011. p. 60-72.

GOMES, Alfredo Macedo; MORAES, Karine Nunes de. A expansão da educação superior no Brasil contemporâneo: questões para o debate. Educação \& Sociedade, Campinas, v. 33, n. 118, p. 171-190, jan./mar. 2012. Disponível em: <http://www.scielo.br/pdf/es/v33n118/v33n118a11.pdf>. Acesso em: 12 mar. 2016.

NÉRES, Alexandre Aparecido da Silva et al. Condições de permanência na Universidade Federal de Rondônia. In: BARBOSA, Jorge Luiz; SILVA, Jailson de Souza e; SOUSA, Ana Inês (Orgs.). Condições de permanência de estudantes de origem popular no espaço acadêmico. Rio de Janeiro: UFRJ, 2010. p. 121-130.

PAULA, Maria de Fátima Costa de. Educação superior e inclusão social na América Latina: um estudo comparado entre Brasil e Argentina. In: PAULA, Maria de Fátima Costa de; FERNÁNDEZ LAMARRA, Norberto (Orgs.). Reformas e democratização da educação superior no Brasil e na América Latina. Aparecida, S.P.: Idéias \& Letras, 2011. p. 53-96.

PAULA, Maria de Fátima Costa de; SILVA, Maria das Graças Martins da. Introdução. In: PAULA, Maria de Fátima Costa de; SILVA, Maria das Graças Martins da (Orgs.). As políticas de democratização da educação superior nos estados do Rio de Janeiro e de Mato Grosso: produção de pesquisas e questões para o debate. Cuiabá: EdUFMT, 2012. p. 720 . 
PAULA, Maria de Fátima Costa de; VARGAS, Hustana Maria. A inclusão do estudantetrabalhador e do trabalhador-estudante na educação superior: desafio público a ser enfrentado. Avaliação, Campinas; Sorocaba, v. 18, n. 2, p. 459- 485, julho, 2013.

PAULA, Maria de Fátima Costa de; HOURI, Mônica de Souza; CRUZ, Andreia Gomes da. Políticas de inclusão na educação superior brasileira: os lugares possíveis dos sujeitos numa sociedade estratificada. In: PAULA, Maria de Fátima Costa de (Org.). Políticas de controle social, educação e produção de subjetividade. Florianópolis: Insular, 2015. p. 193-223.

PINTO, José Marcelino de Rezende. O acesso à educação superior no Brasil. Educação \& Sociedade, Campinas, v. 25, n. 88, p. 727-756, Especial out. 2004. Disponível em: <http://www.scielo.br/pdf/es/v25n88/a05v2588.pdf>. Acesso em: 11 abr. 2016.

PROVIN, Priscila. Inclusão na universidade: estratégias para o ingresso de "todos" no ensino superior. In: FABRIS, Elí T. Henn; KLEIN, Rejane Ramos (Orgs.). Inclusão e biopolítica. Belo Horizonte: Autêntica, 2013. p. 99-111.

RISTOFF, Dilvo. A expansão da educação superior brasileira: tendências e desafios. In: PAULA, Maria de Fátima Costa de; FERNÁNDEZ LAMARRA, Norberto (Orgs.). Reformas e democratização da educação superior no Brasil e na América Latina. Aparecida, S.P.: Idéias \& Letras, 2011. p. 191-216.

RISTOFF, Dilvo. Vinte e um anos de educação superior: expansão e democratização. Cadernos do GEA, Rio de Janeiro, n. 3, p. 3-50, jan.- jun. 2013. Disponível em: <http://www.flacso.org.br/gea/documentos/Cadernos_GEA/Caderno_GEA_N3.pdf>. Acesso em: 12 mar. 2016.

RISTOFF, Dilvo. O novo perfil do campus brasileiro: uma análise do perfil socioeconômico do estudante de graduação. Avaliação, Campinas; Sorocaba, v. 19, n. 3, p. 723-747, nov. 2014.

SILVA, Maria das Graças Martins da; VELOSO, Tereza Christina Mertens Aguiar. Acesso nas políticas da educação superior: dimensões e indicadores em questão. Avaliação, Campinas; Sorocaba, v.18, n. 3, p. 727-747, nov. 2013.

Maria de Fátima Costa de Paula - Universidade Federal Fluminense Niterói |RJ | Brasil. Contato: mfatimadepaula2015@gmail.com 